\title{
LINSKY ON QUINE
}

\section{Dolores Miller}

The difficulty with the chapter on Quine ("Pure Reference" in Referring), is that Linsky's major criticism--that there is no independent criterion, or even sense, to the notion of referential opacity apart from failure of substitutivity--8eems to be justified, while many of his arguments are not. It is sometimes difficult to see the forest (the validity of the principle of substitutivity) for the trees (the details of the arguments).

The principle, as stated by Quine and quoted by Linsky. Is "Given a true statement of identity, one of 1 ts two terms may be substituted for the other in any true statement and the result will be true." But there are certain familiar cases which afford exceptions to the principle, such as contexts of quotation, propositional attitude, modality, and crose-referential demonstrative pronouns. Quine $s$ attempt to fortify the principle against these anomalies, amounts to, as Linsky says, a revision of the principie thus: "Given a true statement of identity, one of its two terms may be substituted for the other at any referentially open position in a true statement, salva veritate." But as Linsky points out, if there is no separate criterion for pure reference (or referential transparency) the attempt is circular. The distinctions of pure and impure reference apparently have no other function but to explain substitutivity or its failure. That is, if we simply relinquish the principle. we would not need these distinctions.

Forestalling this major question. Linsky first examines the form of the relation asserted between substitutivity and reference. Is pure reference a necessary and sufficient condition for substitutivity? Is it first, then, a necessary condition?--given substitutivity, does it always follow there is an instance of pure reference? Linsky offers several counter-examples. The first is the pair. "Cicero" is a designation for Cicero" and "Tully" is a designation for Cicero," where we have ostensibly a case of gubstitutivity without pure reference of the names "Cicero" and "Tully."

It seems possible to build an argument for Quine against this example. In "Reference and Modality" he says, 
an expression which consists of another expression between single quotes constitutes a name of that other expression: and it is clear that the occurrences of that other expression or a part of it. within the context of quotes, is not in general referential. In particular, the occurrence of the personal name within the context of quotes in (4) "Cicero" contains six letters." I is not referential. not subject to the substitutivity principle. The personal name occurs there merely as a fragment of a longer name which contains. besides this fragment, the two quotation marks. To make a substitution upon a personal name, within such a context, would be no more justifiable than to make a substitution upon the term 'cat' within the context 'cattle'.1

Perhaps Quine confuses the issue by speaking of quotation marks as a "context." If we think of quotation marks as a part of the name (which is precisely what he is claiming above), and if we adhere to the letter of the principle which states that one term of an identity statement can be substituted for another. we can see why Quine says these examples are "not subject to the substitutivity principle." For in the case of quotation marks we are not oubstituting the terms of the identity statement, but an entirely new term. Thus to speak of quotation marks as a context is misleading--they seem to be more on a par with prefixes and suffixes, that is, appendages which actually change the term.

Linsky's example seems compelling because it is apparently based on the identity statement, Cicero = Tully, yet if we insist that quotation marks are part of the name, we can say that the terms of the identity statement are not those appearing in his examples. His two examples are not based on an identity statement (since 'Cicero' = "Tully' is simply false) any more than 'Cicero' and 'quoted' in the following sentence pair" "Cicero" has six letters" and "quoted" has six letters." These cases do not illustrate substitutivity in the sense of the principle. that $i s$, on the basis of an identity statement, but are cases where the same thing can be predicated of different subjects. In Word and object2 Quine suggests that the entire error of quotational contexts can be eliminated by resorting to Tarski's method of spelling.

But Quine himself works against this consistent interpretation of what he says above regarding the function of single quotes by continuing:

It would not be quite accurate to conclude that an occurrence of a name within single quotes is 
never referential. Consider the statements (6) "Giorgione played chess' is true, (7) 'Giorgione" named a chess player, each of which is true or false according as the quotationless statement (8) Giorgione played chess, is true or false. Our criterion of referential occurrence makes the occurrence of the name 'Giorgione' in (8) referential, and must make the occurrences of 'Glorgione' in (6) and (7) referential by the same token, despite the presence of single quotes in (6) and (7).3

If we must relinquish our first attempt to defend Quine, at least this shows that he considers such cases to be referential precisely because substitutivity does hold, and Linsky's example is not a refutation.

Linsky's second exampleis "'Cicero' $\neq$ with Cicero," (surely he means "Cicero' $\neq$ Cicero"?) where anything can be substituted in the quotes but would not be purely referential precisely because it is in quotes. We could write this off as one of the exceptions which Quine considers referential even though it is in quotes. But we can be more explicit by showing that in this case again we lack an identity statement--there is not even an attempt to give one. This is another instance which is not subject to the princlple, but shows that something can be predicated of many things.

Another counter-example is based on the identity statement, "King of France = most frequently cited example of a non-existent object." Here Linsky makes the the legitimate substitution in "Charles de Gaulle is not the king of France," but claims that "the king of France" is not purely referential because its object does not exist.

Quine seems to make an explicit distinction between naming and referential occurrences when he discusses quantification in "Reference and Modality", "Yet it is a principle only by courtesy. It holds only in the case where a term names and, furthermore, occurs referentially.

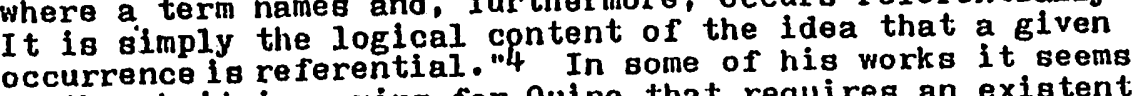
as though it is naming for Quine that requires an existent object. (e.g.. Methode of Logic. Ch. 33. "Existence and Singular Inference") If there is no object, the term fails to name--it merely purports to name. (Quine thus seems to be assuming exactly the distinction which Linsky insists upon in his discuselon of Strawson.5) We could say on the basis of the above that while 'Cerberus' may sometimes occupy a purely referential position, it can never name. Yot in Word and object he says 
Finally, independently of all such technicalities, there is just something wrong about admitting that "Pegasus" can ever have purely referential position in truths or falsehoods, for the intuitive idea behind "purely referential position" was supposed to be that the term is used purely to specify its object for the rest of the sentence to say something about. 6

\section{And in a footnote in Word and Object Quine says}

But note that this use of "name" [applied to "simple" singular terms capable of being reparsed as general terms] is akin to the use in grammar of "proper name." In some writings I have used "name" rather in the sense of "that which naines"--an extragrammatical sense implying existence of a named object. Hochberg. "The ontologlcal operator " pp. 253f., wrongly assumes that $I$ equate the latter or referential sense of namehood with the grammatical one.?

At any rate it seems clear that despite the distinction made in "Reference and Modality." Linsky is correct in saying that for Quine terms are not purely referential if objects are non-existent. Why this has to be the case will be suggested later.

Linsky's final example is in contexts of modality, specifically in "N(9) ?)." Quine, in "Reference ard Nlodality" holds that " 9 " has impure reference because substitutivity fails when we use an identity statement such as "the number of the planets $=9$." Linsky claims that if it has impure reference in " $N(\dot{9}>7)$ " surely it must also in "N(9\$7) " and its true counterpart "-N(9\$7)" The latter remains true under any replacement of " 9 " by any other name for 9. This is another apparent case of substitutivity without pure reference.

ilthough this is one of the classic examples for illustrating the problems of substitutivity, I wonder about the validity of identity statements such as " $9=$ the number of planets" or even "Scott = the author of Waverly." Frege examines three possibilities of what an identity statement could be: (1) a relation between the object designated, thus expressing a relation of a thing to itself $f_{1}(2)$ a relation between the thing. such that they both designate the same object,
(3) a relation between the "senses" or perhapg informational content of the two, such that they both designate the same object. Frege was interested in the latter because it represented synthetic identity statements--two "aspects" or approaches toward the same object, which 
were not merely conventional. But this does not mear tris other two kinds are not also true identity statements. We often come across examples of the other two in disc:sisions of substitutivity, as (1) Scott = Scott, (2) Cicero = Tully. An example of (3) would be "the Horning Star = the Evening Star." In all these examples, the signs on both sides of the Identity sign are of the same kind. In the first, there is the same names in the second. two different names, in the third, two different degcriptions.

Names and descriptions are traditionally lumped together as referring expressions, but it seems to me they can never be members of the same identity statement without the possibility of a kind of equivocation, because they have different primary functions. I name primarily designates or refers, and further is purely conventional, while a description normally predicates--that is, it tells us something about the referent. In Kantian terms, it adds to our concept, in Fregean, it has a "sense," and this is contingent. Of course a name may also do so, when it derives from a description, e.g. "de Tocqueville" or even "Smith" and "Miller" in their original meaning, but this is a secondary or vestigial feature often no longer functioning, and a description may also be used to refer, though thls is a secondary function, used when names are wanting. This is where the troubie starts.

In identity statements of these mixed referring expressions, the primary and secondary functions of the description are confused and application of substitutivity in such cases becomes an equivocation, not of meaning, but of function. In the identity statement, the referential function operates, thus "nine" and "the number of planets" both refer to the same object and in that respect are held to be identical, but such identity statements can also be read as propositions with a subject (designated by a conventional term which refors) and a contingent fact predicated of it (designated by a description). i.e." "nine is the number of planets." or "there are nine planets." And when substituted in a sentence. the normal predicative function of the description may return to operate primarily.

Let us apply this to the problem at hand, the identity statement. "9 = the number of planets" and its substitution into the true modal statement " $N(9>7)$," yielding "N(number of planets $>7$ )" which is false. For Quine this is a case of impure reference because substitutivity does not save the truth value.

But I maintain that if "the number of planets" retains the original secondary function which $1 \mathrm{t}$ has in the identity statement, that $i_{B}$, as a referring expression 
(to the number nine) then $N($ number of planets $>7$ ) remains a true statement. It is only when the identity statement is read as a proposition, that is, where "the number of planets" functions as a contingent predicate, that the modal statement is falsified by substitution. But in that case the "identity statement" is not functioning as an identity statement at all, but is a disguised subjectpredicate proposition. Perhaps the confusion could be eliminated by writing the identity statement as $9=$ the referent of "the number of planets" and the predicative statement as $9=$ the number of planets. Thus $N($ the rererent of "the number of planets" $>7$ ) is true, while $N($ the number of planets $>$ 7) is false.

This shows once more that the key to many of the problems of substitutivity lies in the identity statement. If the identity otatement is genuine, that is, both terms function equaliy to refer, then substitutivity holds, and in Quine's terminology the occurrence of 9 in the modal statement is a case of pure reference--any other expression which functions as a referring expression for 9 may be substituted salva veritate $(e . g ., 9=I X)$. Conversely, expressions which predicate contingent fact of the referent of a name may not be so substituted. It is not only the context which bears watching for cases of reference. but the function of terms in the identity statement.

Linsky concludes on the basis of these counterexanfles that the relation between pure reference and sibstitutivity is not such that the former is a necessary condition for the latter. I have tried to undermine his arguments, but even if we leave him one counter-example he wins his case, and the example of the non-existent "referent" seems to afford a case where substitutivity holds, but by Quine's own standards is without pure reference.

Now Linsky turns to the reverse implication which seems to be the one that Quine consistently and stralghtforwardly claims, 1.e., that substitutivity is a necessary condition for pure reference or. (the equivalent) that if there is failure of substitutivity there is referential opacity. I.insky's argument is this. We assume the following identity to be true of Lyndon. B. Johnson: "The person who holds the office of president of the United States * the person who holds the office of chairman of the Harvard Philosophy Department," and the statement "The person who holds the office of the president of the ir:ited States was administered the oath of the latter office by the Chlef Justice of the supreme Court." But sutstitutivity fails here because the demonstrative expression "the latter office" loses its correct antecedent reference. 
Again Lingky argues that this must be a case of pure reference. "Surely. If there is such a thing as a relation of pure reference at all, the term 'the person who holds the office of president of the United States' stands in that relation to Lyndon $B$. Johnson." 9 But Quine has claimed in a similar example (Giorgione = Barbarelli, and "Giorgione was so-called because of his size," In "Reference and Modality"io) that because substitutivity failed. the terms were not purely referential. Therefore, if Linsky's argument is valid it must be that he is using some other (Intuitive?) criterion for pure reference, although he claims later the notion is a "logical mirage" or a "mere negative after-image." Perhaps the difficulty is that Linsky's claim of pure reference does not consider whether or not this is a referentially open or opaque context--for it is the context which Quine is concerned with-not terms per se.

If we admit Linsky's argument that substitutivity is not a necessary condition for pure reference, then we admit also some other criterion for pure reference which Linsky has not atated if we admit that failure of substitutivity is the criterion for pure reference as in Quine's examples of Giorgione, then this cannot constitute a counter-example and substitutivity is a necessary condition for pure reference.

\section{II}

But let us conceed to Linsky so that we may examine the two alternatives he gives us if we wish to malntain the principle of oubstitutivity. We may first of all try to find another characteristic common to all these heterogeneous cases of failure of substitutivity, or we may admit that we are in a circle and define referential opacity (non-extentsionality) in terms of the failure of substitutivity.

The first alternative fails according to Linsky simply because there doegn' $t$ seem to be any independent cense to "pure reference" apart from substitutivity and the principle it is to explain. But Lingky overlooks an attempt by Quine to give some content to our "intuitive" notion of pure reference. In Hord and Object he says. "In sentences there are positions where the term is used. as a means bimply of speclfying its object, or purporting to, for the rest of the sentence to say spmething about. and there are positions where it is not,"li and later. "...for the intuitive idea bolind 'purely referential poaition' was aupposed to be that the term is used purely to specify its object for the rest of the sentence to say something about."l2 Also, an example, "of purely referen- 
tial position is the position of singular terms under predication." 13

Is Quine suggesting the grammatical role of the subject of predication--at. least as a paradigm? But there are cases where terms are purely referential yet are not grammatical subjects, as in "Crassus heard Tully denounce Cataline," where all three names refer purely, yet only Crassus is the grammatical subject. Nor is it a sufficient condition for being purely referential, for in cases where the object denoted by the subject term does not exist, Quine holds the term to be non-referential. But Quine may have in mind as paradigm for pure reference the logical subject-or those positions which, in symbolic notation, are occupied by variables. So we pass from the vague or intultive notion of subject term to the putative precision of quantified logic.

The claim is that in each of the cases which fail of substitutivity--contexts of quotation, propositional attitude, modality or demonstrative pronouns--quantification produces nonsense. Linsky's counter-example is "Jones believed that somebody stole the jewels" interpreted as Jones believing that some specific, but unnamed person stole the jewels, and which Linsky quantifies as ( Ix) (Jones belleves $x$ stole the jewels). This, he claims, is an example of a case of quantification into an opaque context (belief) which makes perfectly good sense indeed.

Word and Object.

Quine takes pains to deal with just such cases in

The need of cross-reference from inside a belief construction to an indefinite singular term outside is not to be doubted. Thus see what urgent information the sentence "There is someone whom I believe to be a spy" imparts in contrast to "I believe that someone is a spy." Surely therefore. the transparent sense of belief is not to be lightly dismissed.14

But he continues to show that if we allow belief to be invariably transparent we allow more than we intend to. Thus

in general what is wanted is not a doctrine of transparency or opacity of bellef, but a way of indicating selectively and changeably, just what positions in the contained sentence are to shine through as referential on any particular occa- 
So Linsky's counter-example does not automaticall.j: become a case of quantification into an opaque context simply because of the belief context--belief for Quine can also be transparent. But it is just this transparenry which is troublesome to Quine. In "Quantifiers and Propositional Attitudes"16 he considers (1) ( $\mathrm{Jx}$ )(Ralph believes that $x$ is a spy) in the case where falph suspects a man in a brown hat to be a spy, not knowing that he is the same man (say, Bernard $J$. Ortcutt) he has also seen at the beach whom he believes to be a pillar of the community. If we consider the belief in (1) to be transparent (or "relational" as Quine calls it here) which is the only way it makes sense, we are committed to the conjunction (2) Ralph sincerely denies "Bernard J. Ortcutt is a spy" and Falph believes that Bernard J. Ortcutt is a spy.

\section{The reasoning is apparently so :}

Bernard J. Ortcutt $=$ the $\operatorname{man}$ in the brown hat Bernard $\mathrm{J}$. Ortcutt $=$ the man seen at the beach

and given the premisses:

Ralph belleves the man in the brown hat is a spy. Ralph does not believe the man seen at the beach is a spy.

together with the substitutivity allowable if we interpret belief here transparently. we get the seemingly paradoxical conjunction (2) above. Quine does not go so far as to call these statements contrailctory, but he finds them an undesirable "oddity" and he goes to great pains to show that instead of (1) we have another way of quantifyling which gives us the relational sense wanted in ( 1 ). Thus he suggests (Gx)(Ralph believes $z(z$ is a spy) of $x$ )-where $z$ ( $z$ is a spy) is the attribute spyhood.

Yot even with this convention we end by concluding both (3) Ralph believes $z$ ( $z$ is a spy) of Ortcutt and (4) Ralph belleves $z$ ( $z$ is not a spy) of ortcutt, which is surely just as much an oddity as the original troublesome conjunction (2). Thus the whole project does not seem to be a method to avoid the peculiar results of accepting (ax) (Ralph believes $x$ to be a gpy) as transparent--results which lead Quine to relegate that form to nonsense-but rather a device to express the same meaning without quantifying into the belief context. Indeed. the fact that Quine wishes to preserve the relational sense he attributes to (1) seems to prove the point Linsky makes, that (1) makes very good sense. The whole project seems to have no other purpose than to save the purported correlation between a fallure of quantification into belief contexts 
and the opacity of belief contexts. But thls hardly seems necessary if he admits a transparent sense of belief to begin with.

$T$ suspect the attempt to save the parallel between failure of quantification and referential opacity is also the reason why Quine must hold that terms such as "Pegasus" are not purely referential. For by the criterion of substitutivity alone, the following ought to be perfectly acceptable: Since Jupiter = Jove, and "Jupiter was associated.with rain and thunder," then "Jove was associated with rain and thunder." But it is rather the failure of quantification because of its existential implication that leads Quine to reject this as purely referential.

Linsky 's solution to the "oddities" engendered by quantifications such as (Gx)(George IV wishes to know if $x$ is the author of Waverly) (i.e., "George IV wishes to know if Scott is the author of Waverly" as well as "George IV does not wigh to know if the author of Waverly is the author of Waverly") is that both are true, and he explains the apparent paradox of their joint assertion to be supressed relations involved in the identity terms in the scope of a verb of propositional attitude. This appears to be a fruitful, if vague, suggestion, buthis proposed analysis as "George IV wants to know if Scott, under the designation 'Scott' is the author of Waverly" is subject to ambiguity, for surely George IV is not asking whe ther Scott disdained a pen name. (cf. "George IV wishes to know if Mary Anne Evans under the designation 'Mary Anne Evans' is the author of Middlemarch.") But note that Linsky's suggestion is similar to mine in the case of modal contexts regarding 9 and the number of planets, where I suggest $N$ (the referent of "the number of planets">7). Suppose we try my suggestion and use "the referent of : to precede descriptions in true identity statements, $1 . \theta$., Scott $=$ the referent of the author of Waverly'. While it is true that George IV does not wish to know if the author of Waverly is the author of Waverly. it seems to me that George IV could wish to know if the referent of 'the author of Waverly' is the author of Waverly, without being entirely ludicrous. But perhaps this is also subject to ambiguity, for it could be interpreted as asking whether the man reputed to have written Waverly, really did, which is not the issue, any more than 5 cott's pen name. At least Linsky' $s$ and my attempts seem to show the need for a consistent distinction between the referring (or conventional) and predicative (or contingent) functions of a description.

However, the main question of Mlternative I--whether or not failure of quantification might be another criterion for pure reference seems to rest on (1) whether or not 
Quine's alternative devices for quantifying statements like "Jones believes someone stole the jewels" is necessary other than as an ad hoc device to preserve the clajim sary other than as an ad hoc dify into belief contexts, and (2) whe-
that we can't quantify is a we agree that terms with no existent objects cannot
ther we refer.

Alternative II in which we simply define impure reference in terms of failure of substitutivity falls according to Linsky because it cannot account for the invalidity of a certain kind of inference unless the principle is adjusted to include the notion of modality. specifically, logical possibility, and linsky clains this is viclously circular because logical possiblity is one of the contexts that are characterized as opaque.

Linsky's example is the argument, "Alcibiades is the most notorious Athenian traitor. Everyone believes Alcibiades is honest. Therefore, overyone believes the most notorious Athenian traitor is honest."

This is invalid, Linsky claims, for it is at least possible that the premisses be true and the conclusion false. But we can't explain the invalidity on the basis of an 11legal oubstitution into an opaque position in the second premise because that premise 18 false and therefore remains false no matter what you substitute for "Alcibiades." Therefore, by defintion, the context is transparent.

Linsky's argument is not very clear to me, go I will interpret the problem my own way, which arrives, I think, at the same conclusion as Iinsky $B$. Rather than characterize the position as transparent because of its falsity. I prefer to stick to the letter of the principle, which oniy epeaks of substitutivity in true statements. Thus it would seem the principle can't serve as a criterion at all for opaque positions in false atatements generally. and would be of no help in explaining the invalidity of this argument.

But since it is logically possible that the sentence under consideration be true, we can test it for referential opacity on the assumption that it is true. However. this involves another amendment of the original principle to this effect, "...can substitute in any referentially open position in a sentence which is possibly true (in the sense of logical poseiblitty)."

Thus we arrive at the problem Lingky sees. The principle now employs the concept of logical possibility. But this is itself referentially opaque. We have, then, a criterion for referential opacity which includes in it 
an instance of referential opacity.

If my analysis of the necessity statement was correct, we could say that modal contexts are not opaque, but give that impression unless the terms substituted in them are made precise, but even if $I$ am wrong and we concur that modal contexts are referentially opaque, is there a vicious circle?

We are not defining "modality" (least of all logical possibility) by the criterion, but rather what it is to be referentially opaque. And opacity is not a condition for recognizing logical modalities. We define modalities in other ways (perhaps by analyticity). So it is not as though we are defining one notion in terms of the other. Had we used quotation marks in the criterion it would not be circular. All this amounts to is that a position in the criterion would be referentially opaque, but I don't see that it affects the validity of the criterion by making it circular.

Linsky also discusses Quine's argument designed to show that in a case of referential transparency and interchangeability of logical equivalents these two conditions imply the truth-functionality of the statements (extensionality). This is logicaliy equivalent to the claim that departure from extensionality, while allowing interchangeability of logical equivalents leads to the acceptance of referentially opaque contexts. Quine assumes this is a good reason for maintaining extensionality.

But Linsky asks why Quine considers the admission of opaque contexts a dire consequence. Quine feels they lead to the mistake of taking singular terms to occur in contexts in which they are not relevantly present from a logical viewpoint. But again Linsky urges that since there is no other pressing reason for extensionality other than to maintain the principle of substitutivity. perhaps the ansilysis of singular terms which is based on it is overly simple. while the very analysis demanded by referentialiy opaque contexts might be more illuminating.

\section{I I}

The result of this long meandering seems to be that Lingky has shown that pure reference is not a necessary condition for substitutivity, so long as Quine maintains that terms such as 'Pegasus' do not refer, but I don't think he successfully counters the claim that it is a sufficient condition until he produces a separate criterion for pure reference. But he has also pointed out precisely that there does not seem to be any such inde- 
pendent criterion--intuitive notions are illusory, and the claim of failure of quantification into opaque contexts does not hold unless one is determined to maintair. a parallel by ad hoc devices. Neither does it seem to me that Iinsky successfully counters Alternative II--the admittedly "circular" interpretation.

Therefore there do not seem to be any logical reasons to prevent one from maintaining the principle of substitutivity (as duly amended) and its correlative notions, referential opacity or transparency under Alternative II. The issue seems to turn on pragmatics--what is the point of maintaining the principle and its concepts and the machinery required if we do not get beyond their manifest circle. More important, might not such an adherence prevent us from making more faithful and penetrating analyses of the complexities of natural language. As Linsky points out in his concluding section, the logician seems to be precluded from the context of gpeech situations, which includes the knowledge assumptions of both speaker and audience and which are so relevant in analyses of meaning.

University of Missouri at Kansas City 
NOTES

${ }^{1}$ From a Logical Point of View, 2nd ed. (New Yorks Harper Torchbooks, 1963), p. 140 .

2 Word and Object (New York: The Technology Press of M.I.T. and John Wiley and Sons, Inc.. 1960), p. 143.

$3_{\text {LPV, p. } 141 .}$

4 LPV. p. 146.

$5_{\text {Leonard Linsky, Referring (New York, llumanities }}$ Press, 1969), p. 87.

6

7W\&O, p. 180

${ }^{8}$ LPV. pp. 143-144.

9 Referring, p. 104.

${ }^{10}$ LPV, p. 140

$11_{\text {W\&O }}$, p. 141 .

12 W\&O, P. 177

13 W\&O, p. 143 .

14 w\&0, p. 148 .

15 W\&O , p. 149 .

16 The Ways of Paradox (New York: Random House, 1966). 